\title{
Indeterminate Nodule Type
}

National Cancer Institute

\section{Source}

National Cancer Institute. Indeterminate Nodule Type. NCI Thesaurus. Code C157672.

The margin satisfies none of the other categories or cannot be determined with confidence. 